\title{
The natural history and management of hamstring injuries
}

\author{
Chad Carlson
}

Published online: 28 February 2008

(C) Humana Press 2008

\begin{abstract}
Hamstring injuries in sport can be debilitating. The anatomical complexity of this muscle makes uniform assessment of injury epidemiology difficult and insures that post-injury management strategies must be individually focused. This article reviews the anatomy of the hamstring, its role in athletic movement, common mechanisms of injury, and management guidelines with the goal of return into sporting activity in mind.
\end{abstract}

Keywords Hamstring · Injury - Sports · Athlete · Avulsion - Tear - Ischial tuberosity - Semimembranosus · Semitendinosus · Sprinting · Hamstring-to-quadriceps ratio - Eccentric - Nordic hamstring exercises . Epidemiology · Stretching · Inflexibility · MRI · Magnetic resonance imaging · Avulsion fracture . Rupture · Return-toplay · Rehab · Rehabilitation · Physical therapy

\section{Introduction}

Hamstring injuries are common in sports that involve sudden bursts of running, and can be frustrating for both athletes and physicians due to the unpredictability and wide variability of return to play in any given athlete. Of all muscle injuries, hamstring strains have one of the highest recurrence rates [1]. Biomechanical analysis of hamstring function is complex due to its ability to influence movement at multiple joints, which in turn makes identification

C. Carlson $(\bowtie)$

Stadia Sports Medicine, 6000 University Avenue, Suite 250,

West Des Moines, IA 50266, USA

e-mail: ccarlson@stadiasportsmedicine.com;

huskerchad@aol.com of clear risk factors and development of effective injury prevention scenarios a challenge. The purpose of this review is to describe hamstring injuries as they relate to an athletic population and to summarize the current literature with respect to risk stratification, treatment decisions, and prevention of recurrent injury.

\section{Anatomy and biomechanics}

The hamstring is actually a group of four muscles, three of which originate in common at the ischial tuberosity and then diverge to attach distal to the knee. Semimembranosus and semitendinosus originate at the mid-portion of the ischial tuberosity and attach distally at the posteromedial tibia, while the long head of biceps femoris arises from both the lateral portion of the ischial tuberosity and the sacrotuberous ligament and attaches distally at the fibular head, in common with the short head of biceps femoris. The short head of biceps femoris arises from the lateral intermuscular septum and lateral femoral cortex at its distal third.

The multiple attachments of the hamstring allow this muscle to impact function throughout the pelvis and lower extremities. In addition to flexion and extension of the knee, the hamstrings affect pelvic tilt and rotation, sacral rotation and extension and rotation of the hip [2, 3].

Much of the biomechanical analysis of hamstring function has been done using sprinters running on a treadmill [4]. These analyses consistently show that the maximal lengthening of the hamstring occurs at the end of the swing phase of gait, just prior to foot contact, when the hip is flexed and the knee flexion moment is reducing. During sprinting, which involves more hip flexion, this stretch is offset by relatively less knee extension. EMG analysis confirms that the maximal hamstring contraction 
also correlates to this portion of the running phase, as the hamstrings apply a braking force to the quadriceps and hip flexors [5].

\section{Mechanism of injury and injury risk factors}

The period of maximal eccentric contraction in the running cycle, when the muscle is both lengthening and contracting at the same time, seems to carry a higher risk for muscle injury [6]. A low hamstring-to-quadriceps strength ratio will increase the extension moment through the knee, potentially stretching the eccentrically contracting hamstring beyond its elastic capabilities [7]. Most epidemiological studies show a relatively higher rate of injury to the biceps femoris as compared to the medial hamstring muscles $[2,4,8,9]$. This is felt to relate to the fact that the hip and knee flexion moments are less for biceps femoris than for its medial counterparts. The combination of tight musculature and a longer running stride may predispose to injury. Athletes who bend forward at the hips to accelerate while running tilt their pelvis forward and increase tension on the hamstrings [17]. Over-lengthening of the long head of biceps femoris has been documented as the cause of acute hamstring strain in injuries captured on video analysis [6].

Tightness of the iliopsoas is directly responsible for a relative anterior pelvic tilt that places the hamstring at a mechanical disadvantage by increasing the tension at the muscle when the end of the swing phase is reached [2].

Different activities recruit the hamstring in different ways, and the implications for injury also vary. Dancers are frequently injured during static partner stretches [10]. Water skiers are at a higher risk for proximal injury when being pulled out of the water [11]. This occurs if they are forcefully pulled into hip flexion while maintaining their knees fully extended. Hockey players, whose feet are constantly on ice, are thought to develop hamstring problems that stem from core muscle weakness. Weakness of the abdominal muscles allows an anterior pelvic tilt, placing the hamstrings at a mechanical disadvantage that can lead to overuse injury. Marathon runners have been shown to develop decreased eccentric strength at the hamstrings during the course of a race [12].

Most epidemiological research on athletes and hamstring strains has been performed on soccer or Australian rules football players [8, 9, 13-15]. Both sports demand frequent bursts of sprinting over a prolonged period of time, with a higher risk for muscle fatigue. The kicking aspect of these sports also predisposes to a muscle injury that can require more prolonged recovery times, since the forces driving the hip into flexion during the acceleration phase of the kick are relatively greater. Likewise, demand for the eccentric braking action of the hamstring muscles is greater during the kicking motion as well [3].

Risk factors that have been associated with hamstring injury include competition (versus practice), decreased quadriceps flexibility (which keeps the knee relatively extended), older age (which has been shown to be associated with increased hip flexor tightness and increased body weight), over-striding during sprint acceleration, black race, low hamstring:quad ratio, muscle fatigue, hamstring tightness (though it is unclear whether this is a cause or consequence of injury), decreased tendon compliance, later stages of competition, and previous injury, which is consistently one of the highest predictors of subsequent injury risk. The incidence of recurrent injury runs between 12 and $14 \%$ in soccer players, and as high as $30 \%$ in Australian rules football. Premature return-to-play is also cited as a risk [9, 13, 16-18].

Hamstring injuries commonly result in large amounts of time lost to competition. Sprinters have been shown to average 16 weeks for full return, while dancers in the same study averaged 50 weeks [10].

\section{Evaluation}

The diagnosis of hamstring strain is usually readily apparent on clinical exam, with tenderness at the muscle belly, and occasionally subcutaneous ecchymosis or a palpable muscular defect noted. A diagnostic test for biceps femoris strains has been recently described whereby the patient is asked to remove the shoe of the affected leg while standing by levering the heel against the medial tibial border of the contralateral (stance) leg [19].

The need for imaging of suspected hamstring injuries is dependent on the patient being evaluated. Patients with open physes and suspected proximal injury should have radiographs obtained to rule out apophyseal avulsion fractures of the ischial tuberosity. Surgical repair of fractures displaced more than $2 \mathrm{~cm}$ is debated, but advocated by some [20]. Older patients with suspected common tendon rupture should either be sent on for surgical consultation or imaged with MRI to rule out the injury. Delayed repair of proximal hamstring tendon ruptures that have been missed clinically often leads to suboptimal outcomes because of the interval shortening of the muscletendon unit. This shortening can also lead to secondary complications such as sciatic nerve injury or compartment pressure syndrome of the thigh $[21,22]$.

There have been several studies looking at the extent of injury noted on MRI to predict recuperative time. Although it appears that the length of injury noted on coronal views does have predictive value, there has been no clear benefit 
established over clinical evaluation alone [23-25]. MRI has not yet been shown to predict recurrence.

\section{Treatment}

Initially, the treatment of acute hamstring injuries is similar regardless of the mechanism of injury, after which, management tends to diverge based on the activity requirements of the individual. The dictum to rest is intuitive. Otherwise, early treatment goals focus on minimizing intramuscular bleeding and controlling the inflammatory response. Ice massage and compression wraps are both helpful in this regard $[16,26]$.

Anti-inflammatory medication can be used acutely to try to moderate (but not eliminate) the effects of the inflammatory cascade. NSAID use has been shown in animal models to be detrimental to tissue healing when used for long periods of time, but for shorter periods can help to minimize inflammatory-mediated damage to healthy tissue that is peripheral to the injury [16]. Anti-inflammatories also reduce tissue soreness and probably allow earlier progression from total rest to early rehabilitation. Corticosteroids can be administered orally or intramuscularly for acute injuries. It has been suggested through uncontrolled case studies that intramuscular steroid injections speed return to play in professional football players [27]. Balanced against this is the knowledge that corticosteroid injections have the potential to inhibit collagen linkage and slow overall tissue healing [28].

In most studies, prophylactic stretching has not been shown to influence the rate of hamstring injury [29], but stretching after an injury may be more helpful. One controlled study that looked at this found an increased benefit when sets of four hamstring stretches (begun $48 \mathrm{~h}$ after injury) were repeated four times per day in comparison to once per day [30]. Hamstring flexibility tends to decrease after an acute injury [31], in part due to an increase in intramuscular scar tissue formation. Restoration of muscle length reduces eccentric loads that are imposed at peak joint torque once activity is resumed. Stretching the hamstrings with the pelvis maintained in an anterior tilt has been shown to be more effective for muscle lengthening than standard hamstring stretches [30].

There are no controlled studies comparing different return-to-play strategies for hamstring injury [2], though some uncontrolled studies have been published that suggest the value of using objective recovery of strength and optimization of the hamstring:quadriceps ratio determined through isokinetic testing [32, 33]. Functional rehabilitation of hamstring injuries must be tailored to the individual needs of the patient. General goals include restoration of pre-injury muscle strength and flexibility, as well as assistance with pain relief. Supervised strength programs have been shown to reduce the risk of subsequent injury [17]. Gentle concentric strengthening should be initiated first, followed by progressive open-chain eccentric strength exercises. Eccentric strength exercises are more effective than concentric exercise and can assist standard stretching in re-establishing muscle length after injury [34, 35]. The biarticular nature of the hamstring muscle, as well as its wide array of muscle attachments, requires attention beyond the hamstring itself. Abdominal and core muscle strengthening keeps the pelvis in an optimal position for hamstring function and increases the overall stability of the pelvic platform - an important goal for athletes such as hockey and soccer players, who are in closed-chain positions for longer periods of time. Rehabilitation programs that emphasize core stability have been shown to outperform those that focus on isolated progressive hamstring strength training [36]. Return-to-play decisions are usually supported by a measurable return of strength to $90-95 \%$ of pre-injury levels, a demonstrated ability to perform progressive sport-specific challenges without pulling up, and readiness on the part of the athlete. Generally, athletes who are involved in ballistic power activities such as sprinting (with less ability to use other muscle groups to compensate around an injured hamstring) should be held from practice or competition for longer periods of time, until demonstrated strength of the injured leg is approaching that of the uninjured side [1].

Preventative measures such as the Nordic hamstring exercises are advocated for use with athletes wishing to reduce their overall risk of injury. Several early studies have shown an apparent treatment benefit, but these are still awaiting confirmation through larger trials [8, 34]. One interventional study done on Australian rules football players that demonstrated a positive benefit incorporated anaerobic high-intensity running drills, frequent hamstring stretches, sport-specific training drills, and counseling on resistance training after an initial 2-year period of pre-interventional injury analysis [17]. This reinforces the importance of grounding rehabilitation efforts in sport specificity.

Surgical treatment should be reserved for widely displaced avulsion fractures of the ischial tuberosity or complete proximal hamstring tendon rupture. Repair of partial common tendon ruptures has also been shown to obtain good functional outcomes in selected patients who are failing conservative attempts at care.

\section{Conclusion}

Hamstring mechanics are complex, making efforts at predicting injury patterns and developing injury treatment and 
prevention protocols difficult. Efforts at management should incorporate proven standards of acute muscle injury care with rehabilitation efforts that consider the total activity-specific demands on lower extremity and pelvic kinetics.

\section{References}

1. Orchard J, Best TM, Verrall GM. Return to play following muscle strains. Clin J Sport Med. 2005;15:436-41.

2. Thelen DG, Chumanov ES, Sherry MA, Heiderschiet BC. Neuromusculoskeletal models provide insights into the mechanisms and rehabilitation of hamstring strains. Exerc Sport Sci Rev. 2006;34(3):135-41.

3. Fields KB, Bloom OJ, Priebe D, Foreman B. Basic biomechanics of the lower extremity. Prim Care Clin Office Pract. 2005;32:245-51.

4. Thelen DG, Chumanov ES, Hoerth DM, Best TM, Swanson SC, Li L, Young M, Heiderscheit BC. Hamstring muscle kinematics during treadmill sprinting. Med Sci Sports Exerc. 2005;37(1):108-14.

5. Thelen DG, Chumanov ES, Best TM, Swanson SC, Heiderscheit BC. Simulation of biceps femoris musculotendon mechanics during the swing phase of sprinting. Med Sci Sports Exerc. 2005;37:1931-38.

6. Heiderscheit BC, Hoerth DM, Chumanov ES, Swanson SC, Thelen BJ, Thelen DG. Identifying the time of occurrence of a hamstring strain injury during treadmill running: a case study. Clin Biomech. 2005;20:1072-8.

7. Orchard J, Marsden J, Lord S, Garlick D. Preseason hamstring muscle weakness associated with hamstring muscle injury in Australian footballers. Am J Sports Med. 1997;25:81-85.

8. Brooks JHM, Fuller CW, Kemp SPT, Reddin DB. Incidence, risk and prevention of hamstring muscle injuries in professional rugby union. Am J Sports Med. 2006;34(8):1297-306.

9. Woods C, Hawkins RD, Maltby S, Hulse M, Thomas A, Hodson A. The Football association medical research programme: an audit of injuries in professional football-analysis of hamstring injuries. Br J Sports Med. 2004;38:36-41.

10. Askling C, Saartok T, Thorstensson A. Type of acute hamstring strain affects flexibility, strength, and time to return to pre-injury level. Br J Sports Med. 2006;40:40-4.

11. Sallay PI, Freidman RL, Coogan PG, Garrett WE. Hamstring muscle injuries among water skiers: functional outcome and prevention. Am J Sports Med. 1996;24(2):130-6.

12. Koller A, Sumann G, Schobersberger W, Hoertnagl H, Haid C. Decrease in eccentric hamstring strength in runners in the tirol speed marathon. Br J Sports Med. 2006;40:850-2.

13. Gabbe BJ, Finch CF, Bennell KL, Wajwelner H. Risk factors for hamstring injuries in community level Australian football. Br J Sports Med. 2005;39:106-10.

14. Gabbe BJ. Why are oldre Australian football players at greater risk of hamstring injury? J Sci Med Sport. 2006;9(4):327-33.

15. Volpi P. Muscle strains in soccer: a five-year survey of an Italian major league team. Knee Surg Sports Traumatol Arthrosc. 2004;12(5):482-85.

16. Drezner JA. Practical management: hamstring muscle injuries. Clin J Sports Med. 2003;13:48-52.

17. Verrall GM, Slavotinek JP, Barnes PG. The effect of sports specific training on reducing the incidence of hamstring injuries in professional Australian rules football players. Br J Sports Med. 2005;39:363-68.

18. Petersen J, Holmich P. Evidence based prevention of hamstring injuries in sport. Br J Sports Med. 2005;39:319-23.

19. Zeren B, Oztekin HH. A new self-diagnostic test for biceps femoris muscle strains. Clin J Sport Med. 2006;16(2):166-69.

20. Kujala UM, Orava S, Karpakka J. Ischial tuberosity apophysitis and avulsion among athletes. Int J Sports Med. 1997;149-55.

21. Chakravarthy J, Ramisetty N, Pimpalnerkar A, Mohtadi N. Surgical repair of complete proximal hamstring tendon ruptures in water skiers and bull riders: a report of four cases and review of the literature. Br J Sports Med. 2005;39:569-72.

22. Lempainen L, Sarimo J, Heikkila J, Mattila K, Orava S. Surgical treatment of partial tears of the proximal origin of the hamstring muscles. Br J Sports Med. 2006;40:688-91.

23. Schneider-Kolsky ME. A comparison between clinical assessment and magnetic resonance imaging of acute hamstring injuries. Am J Sports Med. 2006;34(6):1008-15.

24. Connell DA. Longitudinal study comparing sonographic and MRI assessments of acute and healing hamstring injuries. Am J Roentgenol. 2004;183(4):975-84.

25. Gibbs NJ. The accuracy of MRI in predicting recovery and recurrence of acute grade one hamstring muscle strains within the same season in Australian rules football players. J Sci Med Sport. 2004;7(2):248-58

26. Thorsson O, Hemdal B, Lilja B. The effect of external pressure on intramuscular blood flow at rest and after running. Med Sci Sports Exerc. 1987;19:469-73.

27. Levine WN, Bergfeld JA, Tessendorf W. Intramuscular corticosteroid injection for hamstring injuries: a 13-year experience in the national football league. Am J Sports Med. 2000;28:297-300.

28. Kennedy JC, Willis RB. The effects of local steroid injections on tendons: a biomechanical and microscopic correlative study. Am J Sports Med. 1976;4:11-21.

29. Thacker SB, Gilchrist J, Stroup DF, Kimsey CD. The impact of stretching on sports injury risk: a systematic review of the literature. Med Sci Sports Exerc. 2004;36(3):371-8.

30. Malliaropoulos N, Papalexandris S, Papalada A, Papacostas E. The role of stretching in rehabilitation of hamstring injuries: 80 athletes follow-up. Med Sci Sports Exerc. 2004;36(5):756-9.

31. Worrell TW, Perrin DH, Gansneder B, Gieck J. Comparison of isokinetic strength of flexibility measures between hamstring injured and non-injured athletes. J Orthop Sports Phys Ther. 1991;13:118-25.

32. Heiser TM, Weber J, Sullivan G. Prophylaxis and management of hamstring muscle injuries in intercollegiate football players. Am J Sports Med. 1984;12:368-70.

33. Crosier J, Forthomme B, Namurois M. Hamstring muscle strain recurrence and strength performance disorders. Am J Sports Med. 2002;30:199-203.

34. Mjolsnes R, Amason A, Osthagen T. A 10-week randomized trial comparing eccentric vs. concentric hamstring strength training in well-trained soccer players Scand J Med Sci Sports. 2004;14:311-7.

35. Brockett CL, Morgan DL, Proske U. Human hamstring muscles adapt to eccentric exercise by changing optimum length. Med Sci Sports Exercs. 2001;33(5):783-77.

36. Sherry MA. A comparison of 2 rehabilitation programs in the treatment of acute hamstring strains. J Orthop Sports Phys Ther. 2004;34(3):116-25. 